\title{
Historia de los Lobbies: una forma de escribir la historia
}

\author{
David Caldevilla DomíngueZ \\ Universidad Complutense de Madrid \\ davidcaldevilla@ccinf.ucm.es \\ Jordi XIFRA TRIADÚ \\ Universidad Pompeu Fabra (Barcelona) \\ jordi.xifra@upf.edu
}

\section{Resumen}

El lobby es un fenómeno con resonancias muy negativas, pero que responde a una necesidad fundamental de influir en las decisiones del poder público desde la esfera privada: necesidad esta que distintas instituciones, empresas y personas han satisfecho desde el comienzo de la civilización.

Palabras clave: Lobby, cabildeo, política, gobierno, influencia, prensa

\section{Lobby's history: a way to write history}

\begin{abstract}
Lobbying is a phenomenon associated with negative terms, but it serves the essential need of influence in the public power from the private sphere: something that several institutions, enterprises and people have satisfied since birth of civilization.
\end{abstract}

Key Words: Lobby, 'cabildeo', politics, goverment, influence, press

\section{Referencia normalizada:}

Caldevilla Domínguez, D. y Xifra Triadú, J. (2013) Historia de los Lobbies: una forma de escribir la historia. Historia y Comunicación Social. Vol. 18. № Especial Diciembre. Págs. 879-892.

Sumario: 1. Introducción 2. Metodología 3. Desarrollo 3.1. Antigüedad. 3.2. El Medievo hacia el Renacimiento 3.3. El Lobby moderno 4. Conclusiones 5. Bibliografía

\section{Introducción}

Existe una falta de información en la sociedad sobre qué es el lobby y cuál es su función ante las Administraciones públicas, debido sin duda al oscurantismo que muchas veces han profesado sus actores. La palabra tiene ecos de injerencia en las decisiones de las esferas ejecutivas del sistema político, ya que se entiende que se procura el beneficio particular de los grupos pueden pagar estos servicios, mediante el logro de la comprensión a sus problemas por parte de los legisladores, algo, que en su filosofía inicial, suena como justo. 
La imagen de estos "grupos de presión", ya que ésta es la traducción más cercana al quehacer de estos 'pasillos' o 'vestíbulos' (que es lo que significa literalmente 'lobby' en nuestro idioma) depende del tono de las noticias que llegan al gran público a través de los medios de comunicación para masas. Incluso en el país donde su labor es, en apariencia, más activa (Los Estados Unidos de América) esta idea popular preconcebida sobre lo artero de su quehacer es la que ha forzado a que sea regulada su labor, lo cual ha logrado que sus actividades sean públicas, que no realmente difundidas. La misma sociedad norteamericana ha pasado apuros para comprender y aceptar un fenómeno que algunos de los llamados Padres de aquella nación veían con malos ojos.

Y sin embargo, tan sólo es necesaria una breve reflexión crítica para percibir que influir sobre las decisiones de un Estado ha sido una necesidad constante en la historia de los pueblos. En otras palabras: las actividades del actual lobby (avant la lettre) pueden ser más antiguas que el lobby mismo:

Desde tiempos remotos se ejercen presiones y se trata de influir sobre los legisladores para favorecer los intereses de un grupo privado determinado.

Es por ello, para dar a conocer los intereses de los públicos privados a los representantes del poder establecido, por lo que es necesaria la existencia del lobby, ya que se acerca la política a las necesidades de sus electores. ${ }^{1}$

La moderna información política ha llamado la atención del gran público sobre el fenómeno: durante las décadas comprendidas entre 1890 y 1920, los reformistas estadounidenses ya denunciaban y se preocupaban por la influencia "corruptora" que estos elementos tenían en el Gobierno norteamericano ${ }^{2}$. Así, ilustres inquilinos de la Casa Blanca, como Eisenhower o Kennedy advirtieron o defendieron esta realidad, lo que alimenta su carácter polémico. Un análisis de los antecedentes históricos podría ayudar al periodista y al ciudadano, a formarse una opinión compleja e informada sobre ello, de cara a un futuro en el que, cada vez más, va integrándose como parte formal del sistema parlamentario moderno y multi-estatal. De hecho, David Dwight Eisenhower, recordemos que exmilitar de brillante carrera, dato que es si cabe, aún más significativo, dijo en una ocasión tras haber llegado a la Casa Blanca:

"En los consejos de gobierno, tenemos que tener cuidado con la adquisición de una influencia ilegítima, deseada o no, por parte del complejo militar-industrial. Existe el riesgo de un desastroso desarrollo de un poder usurpado y [ese riesgo] se mantendrá. No debemos permitir nunca que el peso de esta conjunción ponga en peligro nuestras libertades o los procesos democráticos." 3

1 CAlDEVILla DOMÍNGUEZ, David (2007): Manual de Relaciones Públicas. Madrid. Vision Net.

2 CLEMENS, Elisabeth S. (1997): The People's Lobby: Organizational Innovation and the Rise of Interest-Group Politics in the United States. University of Chicago. Chicago. Disponible en: www. amazon.com/The-Peoples-Lobby-Organizational-Innovation/dp/0226109933\#reader_0226109933. [05-09-2013]

3 MEYSSAN, Thierry (2008): "La continuidad del poder en Estados Unidos, detrás de la Casa Blanca”. Disponible en: www.voltairenet.org/article155706.html. [20-09-2013] 


\section{Metodología}

Dado que el presente artículo estudia un estado de la cuestión, desde sus raíces históricas hasta nuestros días, la metodología empleada es la hermenéutica, o estudio e interpretación de las fuentes desde una óptica lógico-histórico-comparativa, ya que a éstas hay que recurrir para poder evaluar el presente de los lobbies y, tras esta analítica textual, se aplicará el modelo analítico deductivo e inductivo, a fin de extrapolar datos y generar modelos comprensivos de la realidad actual

\section{Debate y discusión}

\subsection{Consideraciones iniciales sobre el origen del lobby}

Cuando las ciudades-estado que fueron cuna de la civilización europea en Grecia e Italia se asomaron más allá de sus asentamientos iniciales, las formas de gobierno primitivas fueron quedando obsoletas; casi todas ellas tenían o terminaron teniendo una forma de Senado o Asamblea. Si bien Roma comenzó siendo una Monarquía (753-509 a.d.C.), una vez desterrada, los cabezas de familia de los clanes principales de la ciudad (patricios) quienes ya conformaban el consejo de ancianos o 'seniles' (de donde 'Senado') como órgano consultivo de los Reyes, pasaron a ostentar todo el poder e incluso a dar nombre a la nación (Senatus populusque romanus -SPQR- o El Senado y el pueblo de Roma). Nada más que "hombres vestidos con pieles, hombres de corazón rústico: cien de entre ellos, en un prado, eran muchas veces todo el Senado" ${ }^{\text {" }}$. Con el tiempo se convirtió en una mezcla ambivalente de Patricios, Caballeros y Gentes de la Plebe. En Esparta, sus dos Reyes coetáneos eran poco menos que decorativos ya que ni era labor suya declarar la paz o la guerra, ni tenían poder para ello. Ni tan siquiera la Gerusía (Senado) de los 28 gerontes (Gerusía -junta de ancianos, en griego-) podía hacer esto solo: requería de otros organismos de control distintos que estaban presentes en la estructura política: cinco individuos escogidos anualmente de entre las clases bajas -los éforos- tenían, en este sentido, más poder que el Senado y los Reyes juntos. Volviendo a Roma, recordemos que la Monarquía es sustituida por un sistema de dos pretores (más tarde llamados cónsules), de modo que uno y otro se controlasen mutuamente a la hora de ejercer el poder ejecutivo supremo.

En las democracias, como Atenas, la complicadísima normativa electoral y gran cantidad de órganos garantizaban el acceso al poder del hombre de a pie: ni tan siquiera la flota podía salir sin un plebiscito, pues eran los ciudadanos quienes remaban en ella.

4 PROPERCIO, Sexto Aurelio (20 a.d.C.): Elegías, $I V$. Traducción de RAMÍREZ DE VERGER, A. (1989). Gredos. Madrid. 
Por el contrario la figura del tirano, defendida por muchos filósofos hoy alabados, era más fácilmente corrompible, pues no tenía a su alrededor medios institucionalizados para ser controlado, ni reprendido. No había previstos mecanismos legales para hacerse valer frente a él. Todo ciudadano que buscase defender su causa ante el unificado poder ejecutivo-legislativo-judicial, no sabía en ningún momento si estaba pagando una tasa, o un soborno; escribiendo una rogatoria, o una insidia que lo hacía cómplice de la propaganda extranjera; ni si su petición sería siquiera escuchada.

Incluso las aristocracias son un límite importante a los poderes centrales y un poderoso medio de influencia sobre las mismas. Todas las leyes medievales que eximen a la nobleza de impuestos, que reconocen su derecho a reclutar y mantener tropas, regular las horas de trabajo que les deben sus súbditos, los otros privilegios especiales, etc... no son más que una versión primitiva de la idea de contrato social: gracias a este acuerdo tácito de poder entre aristocracia y Monarquías, durante siglos existió una ley para el pueblo, bien distinta, es cierto, que la aplicable a sus regentes, quienes tenían sus propios tribunales y sanciones lenitivas, pero, al menos existía un marco jurídico en el que ampararse. Los nobles, como clase en su conjunto, se valían de tener medios para influir en el Rey que era, en última instancia, quien dictaba esas leyes y sentencias, pero que -cosa curiosa- necesitaba a menudo la concurrencia de los nobles y la Iglesia, e incluso la presencia (que no la connivencia) del pueblo llano para subir los impuestos o crear otros nuevos. Lo que se conocía como llamar a Cortes, aunque esta práctica no estaba generalizada aunque el primer caso de Constitución lo podemos encontrar en el Reino de León, derivada de las Cortes del 1188, que son las primeras que pueden tildarse como cuna del parlamentarismo.

\subsection{Evolución del lobby}

Los orígenes más remotos del moderno lobby, en su forma profesional de persuasión e influencia en las cuestiones de gobierno, a favor de terceros, están en las raíces de un oficio de rancio abolengo: el de la abogacía. Y estas raíces están sitas en la Grecia cuna de la democracia, y en un grupo de grandes oradores al que luego la historia y la filosofía de su propio país, han vilipendiado no sin atisbo de razón: los sofistas.

Los sofistas eran oradores de gran talento, consecuencia y producto lógico de la cultura helenística imperante, y su énfasis en la formación del hombre y en el Zoon Politikon o animal político, pues la polis es su entorno natural donde el ser humano como especie puede alcanzar su realización. El hombre es la única criatura que no sólo modifica su hábitat, sino que lo recrea si es preciso y además, desarrolla un nuevo medio de gobernarse y gobernarlo: la política. En este contexto, las diversas Asambleas y Tribunales conformaban un nuevo estatus en el que se decidían cuestiones de todo tipo: desde las triviales sobre la gestión ciudadana, hasta asuntos de vida o muerte, como juicios por delitos graves, declaraciones de guerra. En la parte mercantil hallaremos el germen de los intereses cruzados ya que ciertas políticas 
sobre propiedad, comercio e impuestos podían perjudicar gravemente a unos o a otros.

Los sofistas, considerando que no existía mayor habilidad en el discurso y la oratoria, que ser declarado vencedor de un debate mientras se defiende una postura con la que no se está de acuerdo, alquilaban sus servicios a cambio de postular a favor de una causa u otra. A veces se limitaban a asesorar a quién debía defenderla. De esta forma, individuos y grupos que no contaban con mayoría en las Asambleas griegas, veían a éstas apoyarlos a causa de debates a los que habían acudido suficientemente preparados, pues 'demostraban' que sus respectivas causas eran las justas: "Poder convertir en sólidos y fuertes los argumentos más débiles" tal como lo define una sentencia atribuida a Protágoras.

Ya otros filósofos coetáneos (Sócrates y su cadena de discípulos son los más notorios) cargaron severamente contra estos hombres por lo que hacían. Y en aquel entonces lo que hacían mal -según sus opositores- era defender causas sin importarles lo justas o injustas que éstas fueran, pero también ponerse de parte de lo que hoy llamaríamos "minorías parlamentarias" e inclinar la balanza a su favor, o al menos intentarlo con razonables probabilidades de éxito. En ocasiones, y esto fue percibido por el mismo Platón, las mayorías ejercen la Tiranía sobre los demás, sin ser conscientes de ello. Y eso arrojaba a estos grupos en bazos de los sofistas. Su práctica también implicaba que aquellos con los medios para contratarles tendrían de algún modo una ventaja injusta sobre quienes no disponían de ellos, y es que un argumento que bien podría haberse presentado, no contra los sofistas, sino contra quienes les contrataban, era que si habían tenido que pagar a sus oradores para que defendieran su tesis, era porque no habían conseguido convencerles de la justicia de su causa por ningún otro medio. Hoy está universalmente aceptado que todo el mundo tiene derecho a la mejor defensa posible. ¿Significa esto que Platón y los más grandes filósofos de la antigüedad no compartían esta creencia? Más bien significa que, para ellos, el derecho a la mejor defensa había que ganárselo, convenciendo, al menos, al propio abogado.

En Roma surgió por entonces un nuevo tipo de contrato social llamado 'clientelismo'. Una institución que perdió fuerza con la caída de la República. Los 'clientes' romanos eran ciudadanos o grupos de ellos que se adscribían al servicio de una persona de mayor rango social y económico. Esta relación, que según algunos autores se remonta al mismísimo Rómulo, tiene muchos puntos de parentesco con la que un capo mafioso puede mantener con sus secuaces y sus asociados: consistía en que el patrono ofrecía regalos -generalmente en especie- a sus patrocinados a cambio de su respeto y su servicio.

Aunque estamos hablando de una institución que, al mezclarse con otras tradiciones similares más orientadas a la guerra, como la devotio ibérica de la que había disfrutado Aníbal, o la Gefolgschaft (literalmente 'lealtad') germana, terminó dando a luz al "moderno" vasallaje, la relación no es en absoluto la misma ni implicaba que el cliente tuviera que cometer delitos para el patrono -lo que por otra parte podría haber ocurrido perfectamente, pues el cliente, sobre todo los de estatus más bajo, 
dependía grandemente de esta relación para vivir, y además, ser cliente de un ciudadano convertía legalmente a éste en parte de su gens o familia (que no miembro)pero sí contemplaba la obligación del cliente a acompañar al patrono a la guerra, o la de prestarle servicios políticos. Lo que en tiempo de la República, significaba dos cosas: en primer lugar, conceder al protector su voto en alguno de los múltiples comicios que celebraba la ciudad de Roma o sus provincias; y en segundo lugar, acompañarlo al Foro, donde debía aplaudirle y mostrarse de acuerdo con él en todo. Una especie de sofistas de bajo perfil, que tenían la ventaja, para el patrón, de que ninguna ley prohibía a un patricio presentarse en dichos debates con un pequeño ejército de disciplinados votantes, dejando sin efecto, cualquier medida esgrimida en contra del insigne patricio. Se había inventado el concepto de la disciplina de voto. De nuevo nos encontramos ante un caso en el que individuos particulares -patricios con los recursos para mantener un elevado número de clientes- pueden llegar a manipular, gracias a estos instrumentos, las decisiones de los gobernantes. Incluso cuando un ciudadano perdía un esclavo por tener que liberarlo, tanto daba, puesto que éste pasaba a convertirse, legal y automáticamente, en cliente suyo. Cuando se habla de enfrentamientos en las calles de Roma entre partidarios de una u otra facción, se trataba de los clientes de un grupo de patricios contra los clientes de otro grupo de patricios, tratando de hacer méritos ante su dóminus.

Una cuestión derivada del sistema clientelar, es que funcionaba en dos direcciones: y si eficaz era a la hora de girar las ruedas del Senado y la política, quizá con mayor eficiencia pudo usarse por parte del cada vez más centralizado Gobierno, para mantener tranquilas a las masas, que ante la necesidad y las privaciones acudían a sus patronos para suplir sus carencias, por lo que, controlados gubernamentalmente los patronos -por el medio que fuera- controlados sus clientes. Un verdadero ensayo general de lo que sería la política feudal a la caída del Imperio.

Este modus operandi de los clásicos (es decir: los mecanismos de gobierno griegos, la oratoria, el sofismo y el clientelismo romano, que tuvo así mismo sus precedentes en el resto del mundo clásico, no exento de instituciones parecidas) nos debe llevar a la reflexión: son, en esencia, medios más o menos éticos, pero siempre legales y socialmente aceptados -en sus respectivos ámbitos temporales y formales- de que los particulares pueden influir en los gobiernos, más allá del voto individual de cada uno, o de que lo hagan cuando no existe la posibilidad de emitir ese voto o aportar esa voz.

\section{2.- Del medievo hacia el renacimiento}

La nobleza es la clase social emergente en esta época. Para entender su papel hemos de comenzar por el papel de las Cortes. La tradición medieval del vasallaje había convertido el papel del patrono o Señor en el de un verdadero juez, algo tan sólo ligeramente emanado del clientelismo romano, donde los clientes y el dóminus no podían, legalmente, demandarse el uno al otro ante los tribunales ni declarar los unos en contra de los otros. Así pues, las audiencias en las que un vasallo podía ver a su Señor, y presentar una queja oficial, se habían convertido en simples audiencias de justicia para que los vecinos, vasallos y villanos pudieran atacarse judicialmente. En 
esta relación, el "socio" de inferior estatus social, estaba en una desventaja absoluta, y siguió estándolo mucho tiempo. A estos niveles, los del pueblo llano, no puede decirse que el sistema feudal sirviera para que nadie ejerciera ninguna influencia sobre lo que el poder político decidía, fincando como única alternativa o válvula de escape -y así durante siglos- la Iglesia: el único contrapoder que podía imponerse de alguna manera a los Señores e interceder por la gente de a pie, como de hecho hicieron al conseguir el derecho y el diezmo con el que alimentar sus cenobios y también a los hambrientos. Ésta, recordemos, no era una práctica nueva, pues antes, los patronos romanos eran quienes recompensaban el saludo matutino de sus clientes con cestas de materias en especie, y además, el ciudadano romano sin recursos, había tenido derecho, casi desde los orígenes de Roma, a trigo gratis del Gobierno, con el que sobrevivir. Haciendo a los romanos pobres clientes de facto, del Senado primero, y del Emperador después.

Decio Junio Juvenal (60-128) lo explicita, aludiendo al 'opio del pueblo' de la época: el panem et circenses, en su Sátira X (77-81)

"Hace ya mucho tiempo, de cuando no vendíamos nuestro voto a ningún hombre, hemos abandonado nuestros deberes; la gente que alguna vez llevó a cabo comando militar, alta oficina civil, legiones - todo, ahora se limita a sí misma y ansiosamente espera por sólo dos cosas: pan y circo" (Juvenal, 302)

Ahora la Iglesias recogía el testigo; no de la tradición clientelar, sino de la influencia sobre el poder. Un ejemplo claro, es la tradición de 'acogerse a sagrado', según la cual, un delincuente condenado, dado a la fuga, podía refugiarse en una iglesia y pedir derecho de asilo. Una vez hecho esto, los alguaciles competentes, poco podían hacer, salvo esperar a que el reo abandonaba el recinto del templo.

Sin embargo, conforme se acercaba la Baja Edad Media y el renacimiento, algo iba a cambiar: la paz comenzó a ser la norma en muchos territorios, las ciudades volvieron a prosperar, y los centros de poder se fueron desplazando poco a poco, de los castillos a éstas. En los burgos, el incremento de la población, de la capacidad de trabajo, impuestos y del volumen de comercio y productos, comenzó a generar el flujo de dinero que hizo a los reyes percatarse del cambio. Los artesanos y mercaderes vieron la oportunidad de influir: los gobiernos querían algo de ellos -dinero y personal de leva-, y si se limitaban a quitárselo por la fuerza, matarían la gallina de los huevos de oro. Los burgueses (clase emergente o mejor irruptora) iban a tener su moneda de cambio.

Los gremios de las ciudades nacieron, crecieron y fueron ganando privilegios propios y fueros especiales. Ahora, además de una ley para el pueblo, otra para la aristocracia, y una más para en entorno clerical, existía, al menos, un apéndice separado para cada ciudad grande. Los burgueses iban a acabar convirtiéndose en los principales creadores, poseedores y transmisores de riqueza en occidente. El dinero había igualado a nobles y plebeyos. 


\section{3.- El lobby moderno}

Aún tendrían que transcurrir muchos años antes de la aparición del lobby actual: un fenómeno íntimamente ligado a los regímenes parlamentarios de la era industrial. Hay consenso en que el fenómeno cristalizó, y el término empezó a usarse en el siglo XIX con el auge de las democracias anglosajonas:

El lugar de nacimiento del lobbying institucionalizado no ha sabido concretarse: para unos el Reino Unido, para otros Estados Unidos de América. Alonso Piñeiro, después de recordar que el término "lobby" significa los salones situados antes del recinto de sesiones de la Cámara de los Comunes en el Reino Unido del siglo XVIII, donde se daban cita los representantes de distintos intereses comerciales para conversar con los parlamentarios a fin de obtener favores, sitúa el nacimiento del lobbying como institución parlamentaria en febrero de 1884 en Londres.

En 1829, en el ya independiente Estados Unidos, los términos "lobby" y "lobbyagents" se usaban corrientemente. La profesión de estos intermediarios (Mayoritariamente abogados) tuvo un rápido desarrollo en Washington y en las capitales de los estados, debido sobre todo al debilitamiento del poder ejecutivo a favor del legislativo $(\ldots)^{5}$

Pero no será sino hasta finales de ese siglo cuando la práctica se reconociera y se regulase, al menos en parte, de la mano de las cámaras estadounidenses, a fin de diferenciar la presión legítima de la corrupta

La iniciativa reguladora del lobbying se remonta al siglo pasado en los Estados Unidos. Ya en 1876, la Cámara de Representantes adoptó una resolución que exigía el registro de los lobbistas en el secretariado de la Cámara (cuestión básica en toda propuesta de regulación, vigente hasta nuestros días); obligación que fue impuesta seguidamente en varios estados de la Unión. El recelo, justificado por ciertas pruebas documentales, ante la corrupción política encubierta por la presión legítima, provocó la primera propuesta legislativa en 1913 (...) hubo que esperar hasta 1946, año en que se dictó la "Federal Regulation Lobbying Act" (hoy muy desarrollada con la promulgación de la "Lobbying Disclosure Act" de 1995)

Históricamente hablando la primera legislación efectiva se daría en el Estado de Georgia en 1877, tipificándolo como delito y más tarde en el Estado de Massachusets, en 1890 donde se reguló, primerizamente, su actividad.

La democracia norteamericana busca separar la influencia legítima sobre el poder legislativo, de la ilegítima. En Estados Unidos, las prácticas lobbisticas están amparadas desde hace doscientos años en el Derecho de Petición (Right to Petition) que es el derecho que todo ciudadano norteamericano tiene, amparado por la primera enmienda a su Constitución, como parte conformante de la libre expresión. Consiste en poder presentar al Gobierno solicitudes y quejas para que sean escuchadas. Según una jurisprudencia muy repetidamente asentada por los tribunales de ese país, las empresas son sujeto de ese derecho, como si de cualquier ciudadano particular se

5 XIFRA, Jordi (1998): Lobbying: como influir eficazmente en las decisiones de las instituciones públicas. Gestión 2000. Barcelona. 
tratase. Lo que es muy chocante, sabiendo que, quienes redactaron la constitución americana, entre ellos James Madison, quien llegaría a ser el $4^{\circ}$ presidente de la nación (1809-1817), habían tratado de limitar el interés de los sectores particulares por interferir en el gobierno de la nueva República. Por ello, la intención de los llamados "Padres fundadores", al crear la constitución, era precisamente evitar el control del nuevo Estado por parte de individuos poderosos socialmente. Madison consideraba que las facciones (grupos de ciudadanos que en representación de minorías o mayorías buscan imponer intereses que perjudican los derechos de otros ciudadanos) eran peligrosas para la democracia.

Estos "grupos de presión" podían dedicarse a ejercer su labor a favor de causas comprensibles, o a veces incluso triviales, pero siempre relacionadas con la mejora de individuos o empresas ${ }^{6}$.

A principios del XIX, la mayor parte de los lobbies en el nuevo país operaba a nivel de las administraciones y cámaras de los Estados. Sólo en los últimos años del siglo y comienzos del XX sus actividades se ampliaron definitivamente al gobierno federal. Además, en todos los ámbitos, se practicaba de manera discreta, con poco o ningún conocimiento por parte del público. ${ }^{7}$

Entre 1890 y 1920 (recordemos el intento de regulación de 1913) desde distintos ámbitos se culpaba a los lobbistas de corromper a los políticos ${ }^{8}$. Un efecto derivado en gran parte de esa gestión discreta con que el lobby se había estado conduciendo. En 1953, a raíz de una comisión de investigación del Congreso y una sentencia de la Corte Suprema, se diferencian ya dos tipos de lobbying: el directo (reuniones con los representantes y comparecencias ante las comisiones de las Cámaras por parte de los agentes de los grupos) y el indirecto: convencer a la Opinión pública para que sea ésta la que presione al legislador: algo profundamente ligado a la libertad de expresión, según la Corte Suprema.

Siendo Senador por Massachusets, John F. Kennedy (más tarde $35^{\circ}$ Presidente de los EE.UU.) los defendía así:

6 Cuanto más se profundiza en los diversos sectores económicos, más hallamos la sombra del lobby. Así, por ejemplo, citaremos una investigación desarrollada en 2006 en la Universidad Complutense se pudo comprobar que los sectores médico-farmacéuticos incluían cada vez más productos para cirugía estética. Para completar esta información recomendamos se consulte: CALDEVILLA DOMÍNGUEZ, David (2007): "La imagen de la cirugía estética y su presencia en los medios de comunicación" en Revista de comunicación de la SEECI, $\mathrm{n}^{\circ}$ 14. Disponible en: www.seeci.net/ revista/hemeroteca/Numeros/Numero\%2014/Caldevilla.pdf [07-09-2013]

7 DE KIEFFER, Donald E. (2007): The Citizen's Guide to Lobbying Congress: Revised and Updated. Chicago Review Press. Chicago -EE.UU.-. Disponible en: http://books.google.es/books ? id=_8BuewFmfZEC\&printsec $=$ frontcover $\& \mathrm{dq}=\% 22$ lobbying $\% 22 \& \mathrm{hl}=\mathrm{en} \& \mathrm{sa}=\mathrm{X} \& \mathrm{ei}=\mathrm{O}$ $40 \mathrm{PT}$ reG8f $\mathrm{fv} 0 \mathrm{gGUlbmOAw} \&$ redir_esc $=\mathrm{y} \# \mathrm{v}=$ onepage $\& \mathrm{q}=\% 22$ lobbying\%22\&f=false. [05-09-2013]

8 CLEMENS, Elisabeth S. (1997): The People's Lobby: Organizational Innovation and the Rise of Interest-Group Politics in the United States. University of Chicago. Chicago. Disponible en: www. amazon.com/The-Peoples-Lobby-Organizational-Innovation/dp/0226109933\#reader_0226109933. [05-09-2013] 
"Los lobbistas tienen como función, en la mayoría de las ocasiones, explicar de forma clara y explicativa complejas cuestiones. Ellos deben entrar en discusiones personales con los miembros del Congreso a los que explican con detalle las razones de las posturas y posiciones por las que ellos abogan.

Los lobbistas preparan informes, memorandos, análisis legislativos, borradores para el uso de los diversos comités y miembros del Congreso; ellos son necesariamente maestros en su ámbito...". 9

También sabemos, por el posteriormente malogrado Presidente, que estos profesionales eran capaces de explicarle en diez minutos lo que sus asesores tardaban tres días en hacerle entender. Pero el lobby estadounidense estaba a punto de cambiar: con el avance del siglo, los congresistas gastaban cada vez más tiempo en recaudar dinero para la reelección, que iba requiriendo campañas más y más caras debido a la necesidad de presencia en grandes medios televisivos. Así, los lobbies, que se habían centrado hasta entonces en influir sobre parlamentarios ya elegidos, comenzaron a apoyar a "miembros de la Cámara predilectos" en Comités de Acción Política con el objetivo de recaudar fondos ${ }^{10} \mathrm{y}$ asegurar su elección (hábil jugada, ya que sus patrocinados no son cargos públicos aún y su control legal es mucho menor). La complejidad de las nuevas leyes -hay senadores americanos que han reconocido ante el mundo que no se leen la mitad de lo que aprueban- llevó también a otro fenómeno que el cine ha hecho famoso: los "earmarks": añadir adendas a una ley en el último minuto antes de ser aprobada, a fin de desviar fondos a otros proyectos más impopulares.

Incluso los tratados internacionales de los EE.UU. están salpicados de su acción, como la devolución del Canal de Panamá a soberanía panameña como recuerda Guerra Gómez:

"La firma de los tratados en Washington, en el verano de 1977, por los que los Estados Unidos corrigen un error y terminan con una injusticia histórica (...) [con la] oposición de panameños progresistas a un tratado hipotecado; de los norteamericanos destacados, 'zonianos' y funcionarios civiles, que ven peligrar sus cómodos puestos de trabajo. La lucha no es menor a nivel de Capitolio Washingtoniano: republicanos y demócratas conservadores, amén de destacados políticos y senadores (Reagan, Kissinger, Murphy, Goldwater, Hayakawa, De Concini). Sin olvidar a grupos económicos y de presión: lobby de Miami (relaciones torrijistas con Castro), multinacionales como la Standard Fruit Co. e incluso división entre congregaciones religiosa (mormones, baptistas). Los intereses militares v estratégicos se expresan contundentemente por Pentágono y altas instancias del Departamento de Defensa (pagamos por él y el Canal es nuestro). Los apoyos, de calidad e internacionales: Cárter y su Gabinete. Partido Torrijista y gobiernos de la OEA. Resultado del envite: aprobación en el Senado por 62 votos contra 32. El proyecto se había salvado con éxito. Solo quedaba esperar y repasar los contenidos formales, el espíritu pero también la letra,

9 CAldEVILla DOMÍNGUEZ, David (2007): Manual de Relaciones Públicas. Madrid. Vision Net. 10 HESSENIUS, Barry (2007): Hardball Lobbying for Nonprofits: Real advocacy for nonprofits in the new century. Palgrave Macmillan. Londres. 
para calibrar las verdaderas ventajas e inconvenientes de tan magna conquista sobre la tradicional política del good neighborhood [o de buena vecindad]."1

Los lobbies han alcanzado tanto desarrollo en las últimas décadas del siglo XX, que la necesidad de personal ha llevado a reclutar como agentes a una nueva fuente de recursos humanos: los ayudantes de senadores y congresistas, cargos que antes se mantenían durante decenios, ahora quedan vacantes a los pocos años cuando sus ocupantes se pasan al sector privado, dado su mayor y mejor conocimiento del entramado interno de las Cámaras, el 'quién es quién' de las mismas y las inclinaciones de sus señorías y de los candidatos a sustituirles ${ }^{2}$. Otro tanto se puede decir de antiguos congresistas y ex cargos electos del poder legislativo. Una práctica antes mal vista (aunque nunca prohibida). Baste un dato: ya en el año 2007 doscientos antiguos miembros de las Cámaras trabajaban en lobbies ${ }^{3}$ atraídos por unos sueldos muy incrementados a causa de la superior demanda del servicio.

La situación en España ha alcanzado en los últimos años un nivel propio de un sensu lato ya que a la hora de tildar algo como lobby, se hace para desacreditar (aprovechando su mala prensa) situaciones que afectan incluso a la enseñanza, argumento esgrimido por Canosa ${ }^{4}$ para atacar lo que él consideraba como medidas de mejora poco afortunadas:

“Algunos científicos españoles (según el manifiesto "Pacto de Estado por la Ciencia"), constituidos en verdadero lobby, sostienen que el atraso secular español en ciencia y tecnología se debe al escaso presupuesto estatal y al bajo número de investigadores en los Organismos Públicos de Investigación (OPI). Están llevando a cabo una intensa campaña para convencer al gobierno de que en 2010 el presupuesto de ciencia y tecnología debe ascender al 2\% del PIB. Afirman que esto es necesario para que España "no pierda el tren del futuro, que es la economía basada en el conocimiento'."

Es decir, la mala imagen de los lobbies ayuda a culparlos de cualquier solución que se pretenda. Este staus quo en el que nos hallamos en estos momentos es debido a la ausencia de una campaña de información sobre su naturaleza y actividades. Algo, a lo que el cine tampoco ha contribuido (títulos como Gracias por fumar -2005-, La

1 GUERRA GÓMEZ, Amparo (2000): “La sociedad panameña ante el 2000: política y actualidad” en Revista de la SEECI, $\mathrm{n}^{\circ}$ 6. Disponible en: www.seeci.net/revista/hemeroteca/Numeros/Numero\%206/ AmpaGue.pdf [10-09-2013]

2 KAISER, Robert G. y CRITES, Alice (2007): “Citizen K Street: How lobbying became Washington's biggest business. Big money creates a new capital city. As lobbying booms, Washington and politics are transformed". Artículo publicado el 8 de abril en el diario Washington Post. Disponible en: http:// blog.washingtonpost.com/citizen-k-street/chapters/conclusion/ [03-09-2013]

3 KAISER, Robert G. y CRITES, Alice (2007): “Citizen K Street: How lobbying became Washington's biggest business. Big money creates a new capital city. As lobbying booms, Washington and politics are transformed". Artículo publicado el 8 de abril en el diario Washington Post. Disponible en: http:// blog.washingtonpost.com/citizen-k-street/chapters/conclusion/ [03-09-2013]

4 CANOSA, José (2006): "El cambio necesario del sistema universitario y científico español" en Revista Vivat Academia, $\mathrm{n}^{\circ}$ 71. Disponible en: www.vivatacademia.net/h/anteriores/n71/Num71/ PDFs/n71-3.pdf [01-09-2013] 
cortina de humo -1997-, El informe Pelícano -1993-, Syriana -2005-...) ni las series de televisión (El ala oeste de la Casa Blanca -1999 al 2006-) ni los documentales referidos a las acciones de la Casa Blanca (Vender la guerra -1997-) por el ancho mundo.

\section{Conclusiones}

En España la acción de los lobbies es más desapercibida que en otros países sajones, verdaderos inventores del término y su contenido. La palabra "cabildeo" es la más cercana a lobbying que tiene el idioma español. Hace referencia a los cabildos o ayuntamientos, claro, y más concretamente a la actividad de acudir a los mismos con intenciones lobbísticas. Se ha vendido como similar a que uno o varios vecinos acudan a la institución para hablar con un edil o con el alcalde para tratar un asunto que los afecta y "presionarle" para que vea las cosas desde su propio punto de vista: ya sea una expropiación de tierras, la recalificación de un terreno, quejas formales sobre la gestión del regidor, el estado de una calle, un monumento, etc... No olvidemos que esta es una práctica que aún hoy se lleva a cabo y que no hay delito mientras no haya comisión o nepotismo de por medio.

El poder de los lobbies llega hasta donde llegue la Administración sobre la que trabajan y hasta donde ésta les deje llegar. Al decir John F. Kennedy que alababa la rapidez y claridad con que los lobbistas exponían sus argumentos, obviaba el hecho de que lo hacen de manera partidista (como cualquier persona haría) pues la objetividad, citando ahora a Iñaki Gabilondo, es un ideal, no una meta alcanzable. Legalizar y hacer visible al lobby lo transformó de oscura fontanería política, a labor propia de empresas responsables con la ética de sus acciones, localizables ante la justicia y sensibles los juicios paralelos en prensa. Pero en última instancia, los políticos siguen siendo elegidos por la gente, y se espera de ellos que no deleguen las tareas de gobierno en grupos privados o directamente caigan en cohecho. Escándalos actuales como el de la operación saqueo, la malaya, informe Palau de la Música, el entramado Gürtel, casos Pujol, Camps y Bárcenas, juicio a Urdangarín o los ERE en Andalucía exigen que se regule la función de quienes se acercan al poder político con luz y taquígrafos.

Si hemos comprobado en este repaso a la historia que avant la lettre, el concepto lobby camina parejo a las instituciones creadas por el hombre, tomaremos por admisible que las empresas busquen presionar a los Gobiernos como lo sería por parte de cualquier ciudadano que se vea afectado por un decisión o ley. Actualmente, los lobbies tienen una importante presencia en el parlamento Europeo, donde han sido regulados acorde a derecho; tienen acceso a legisladores y Gobiernos para informar sobre su situación e intereses y finalmente tratar de influir sobre ellos. Pero como ciudadanos debemos exigir que se nos informe sobre quiénes, qué es lo que hacen y para quién. La democracia está en juego. 
No deseamos concluir este artículo sin considerar que la labor del lobby puede ser tomada como puramente mercantilista pero no siempre (aunque sí instrumental, obviamente). De hecho, en la enseñanza superior se ha planteado como reto, dentro del área y titulación de las Relaciones Públicas, explicar a los discentes qué es y en qué consiste, ejemplificando con la defensa de ideales no mercantiles, sino basados en una sincera predisposición al bien común, inicial puerta de entrada óptima para este tipo de propuestas. Así, ya en 2009 escribíamos que:

"Una de nuestras metas desde el comienzo fue plantear campañas de imagen sobre los temas que considerábamos de utilidad o interés para los españoles y que, años más tarde, podían ser susceptibles de convertirse en el quehacer diario de los graduados ya que su interés social hacia que fueran apetecibles para las grandes compañías de lobby, imagen y comunicación en las que muchos llegarían, o al menos eso esperaban, a trabajar."'5

Éste es el espíritu con que se debería entender y tender hacia la función de lobby, es decir, el propio de una función de información y concienciación desde el pueblo, y sus empresas (idealmente gratuita, pues son los poderes democráticos quienes deberían facilitar ese acercamiento a todos sus representados), hacia los legisladores electos.

\section{Bibliografía:}

CALDEVILLA DOMÍNGUEZ, David (2007): “La imagen de la cirugía estética y su presencia en los medios de comunicación" en Revista de comunicación de la SEECI, $n^{\circ}$ 14. Disponible en: www.seeci.net/revista/hemeroteca/Numeros/ Numero\%2014/Caldevilla.pdf [07-09-2013]

CALDEVILLA DOMÍNGUEZ, David (2007): Manual de Relaciones Públicas. Vision Net. Madrid.

CALDEVILLA DOMÍNGUEZ, David (2009): "Relaciones Públicas: Iberismo y Prospectiva" en Revista Vivat Academia. no 107. Disponible en: www.vivatacademia.net/h/numeros/n107/Num107/PDFs/n107-1.pdf. [07-09-2013]

CANOSA, José (2006): "El cambio necesario del sistema universitario y científico español" en Revista Vivat Academia, $\mathrm{n}^{\circ}$ 71. Disponible en: www.vivatacademia. net/h/anteriores/n71/Num71/PDFs/n71-3.pdf

CLEMENS, Elisabeth S. (1997): The People's Lobby: Organizational Innovation and the Rise of Interest-Group Politics in the United States. University of Chicago. Chicago. Disponible en: www.amazon.com/The-Peoples-Lobby-Organizational-Innovation/dp/0226109933\#reader_0226109933. [05-09-2013]

DE KIEFFER, Donald E. (2007): The Citizen's Guide to Lobbying Congress: Revised and Updated. Chicago Review Press. Chicago. Disponible en: http://books.

5 CALDEVILla DOMÍNGUEZ, David (2009): "Relaciones Públicas: Iberismo y Prospectiva" en Revista Vivat Academia. n $^{\circ}$ 107. Disponible en: www.vivatacademia.net/h/numeros/n107/Num107/ PDFs/n107-1.pdf. [07-09-2013] 
google.es/books?id $=8$ BuewFmfZEC\&printsec $=$ frontcover $\& \mathrm{dq}=\% 22$ lobbyin$\mathrm{g} \% 22 \& \mathrm{hl}=$ en\&sa $=$ X\&ei $=$ o40PT-reG8fv0gGUlbmOAw\&redir_esc $=\mathrm{y} \# \mathrm{v}=$ onepage $\& \mathrm{q}=\% 22$ lobbying $\% 22 \& \mathrm{f}=$ false. [05-09-2013]

HESSENIUS, Barry (2007): Hardball Lobbying for Nonprofits: Real advocacy for nonprofits in the new century. Palgrave Macmillan. Londres.

JUVENAL, Decio Junio (circa 100): Sátiras. Consejo superior de investigaciones científicas. Madrid.

KAISER, Robert G. y CRITES, Alice (2007): “Citizen K Street: How lobbying became Washington's biggest business. Big money creates a new capital city. As lobbying booms, Washington and politics are transformed". Artículo publicado el 8 de abril en el diario Washington Post. Disponible en: http://blog.washingtonpost.com/citizen-k-street/chapters/conclusion/ [03-09-2013]

MEYSSAN, Thierry (2008): "La continuidad del poder en Estados Unidos, detrás de la Casa Blanca". Disponible en: www.voltairenet.org/article155706.html. [20-09-2013]

PROPERCIO, Sexto Aurelio (20 a.d.C.): Elegias, $I V$. Traducción de RAMÍREZ DE VERGER, A. (1989). Gredos. Madrid.

XIFRA, Jordi (1998): Lobbying: como influir eficazmente en las decisiones de las instituciones públicas. Gestión 2000. Barcelona. 